Revista Docência do Ensino

Superior

v. 3,2013

Madalena Martins Lopes Naves UFMG

madalena.naves@gmail.com

\section{CONSIDERAÇÕES SOBRE A PARTICIPAÇÃO DE DOCENTES UNIVERSITÁRIOS EM BANCAS EXAMINADORAS}

\author{
CONSIDERATIONS ON THE PARTICIPATION OF \\ UNIVERSITY PROFESSORS IN EXAMINING \\ COMMISSIONS
}

\begin{abstract}
RESUMO
Discute o fazer do docente universitário e suas formas de atuação, tendo como foco o papel do orientador e sua participação no processo de orientação, que culmina com o momento da defesa dos trabalhos acadêmicos de graduação e de pós-graduação, lato sensu e stricto sensu, e sua participação em bancas examinadoras. Levanta questões como o papel e a função dos membros dessas bancas, destacando aspectos como responsabilidade e contribuição que se espera dos mesmos para a qualidade dos trabalhos. Cita a importância do compromisso que deve ser assumido diante do examinando e dos outros membros das bancas, além das etapas a serem seguidas na avaliação. Aborda aspectos como ética e relacionamento interpessoal entre professores que participam de bancas.
\end{abstract}

Palavras-chave: Docente universitário. Orientação. Trabalhos científicos. Bancas examinadoras.

\section{ABSTRACT}

It discusses the making of university professor and their ways of working, focusing on the role of advisor and their participation in the guidance process, culminating with the moment the defense of academic papers undergraduate and postgraduate, lato sensu and stricto sensu, and their participation in examining commissions. It raises issues such as the role and function of the members of these commissions, highlighting aspects such as responsibility and contribution expected of them to the quality of the works. It cites the importance of the commitment that must be taken before the examining and the other members of the commissions, and the steps to be followed in the evaluation. It addresses issues such as ethics and interpersonal relationships among professors participating in examining.

Keywords: Microbiology. Practical classes. New methodologies. 


\section{INTRODUÇÃO}

No momento em que a universidade brasileira se vê diante de mudanças profundas em sua estrutura e seu funcionamento, nos mais diversos níveis de abrangência, se faz premente a discussão sobre o fazer de seus docentes e suas formas de atuação.

No contexto do ensino, destacam-se iniciativas relacionadas à formação docente e ao aspecto da qualificação do professor de ensino superior, surgindo, aí, uma questão que ainda não recebeu destaque nas discussões sobre o tema, que é o papel do orientador e sua atuação no processo de orientação, que culmina com o momento da defesa dos trabalhos acadêmicos e sua participação em bancas examinadoras, sendo este o foco a que este ensaio se propõe.

A formação de bancas examinadoras deve obedecer às normas acadêmicas definidas pelas universidades, e depender do nível de atuação, variando na graduação, com a defesa de monografias e trabalhos de conclusão de curso, e na pós-graduação lato sensu e na stricto sensu, com a defesa de monografias, dissertações e teses. Essa atuação engloba procedimentos relativos à definição do número de membros a compor cada banca, à titulação dos docentes, bem como à formação das bancas por membros externos ou internos ao curso ou programa, dentre outros aspectos específicos para cada nível acadêmico.

Além do professor orientador do trabalho acadêmico, que passa a ser o presidente da banca, o procedimento comum é que esta seja composta também por outros dois professores, no caso das bancas examinadoras da graduação. Já no caso dos cursos de pós-graduação, compõem a banca o professor orientador e mais dois professores, para as defesas de dissertação de mestrado, e a banca de defesa de doutorado é composta por cinco professores, sendo o professor orientador mais quatro outros membros. Em todos os casos são convidados membros suplentes. Cabe, aos coordenadores dos cursos ou dos programas de pósgraduação, a competência de revalidar as indicações de nomes para compor tais bancas, sendo este um ato administrativo.

Nesse sentido, merecem reflexão aspectos que não estão definidos nas referidas normas acadêmicas, nem tampouco são lembrados na organização interna e no planejamento dos cursos de pós-graduação. Esses aspectos se referem ao comportamento humano e à questão da ética no ambiente profissional do docente universitário.

Qual é o papel dos membros de bancas examinadoras? Que função eles exercem? Além dos aspectos administrativos anteriormente mencionados, vale ressaltar 
que se trata de importante papel, carregado de enorme responsabilidade, não só no que se refere às etapas de trabalho, mas, principalmente, pela avaliação criteriosa que deve ser feita, com vistas à contribuição que o trabalho do aluno deverá representar para a área e para o seu crescimento profissional.

Segundo Paganelli (2011),

O examinador deve sempre valorizar o mérito científico do trabalho apresentado. Para que seja feita uma análise correta nesse sentido, é pertinente que se faça algumas perguntas, entre elas: por que o trabalho foi realizado? Era preciso realizá-lo? A metodologia foi a mais adequada? O tratamento dos resultados foi adequado? A revisão de literatura realmente foi analisada e criticamente explorada na discussão? O trabalho, no todo, está bem apresentado e padronizado conforme as normas da casa?

Os examinadores devem seguir algumas etapas, desde a aceitação do convite para participação, até o momento da defesa do candidato, momento considerado relevante e conclusivo em todo o processo.

Pode-se considerar que a participação de novos docentes em bancas tem ocorrido de forma leiga, já que não se tem verificado, por parte das universidades, preocupação ou investimento na preparação dos docentes para esse fim.

No seu cotidiano, os docentes de nível superior acumulam inúmeros compromissos, que incluem carga horária didática, cargo administrativo na própria unidade ou em órgãos superiores, desenvolvimento de pesquisas, redação de artigos científicos, orientação de alunos de graduação e pós-graduação, dentre outras. Essa orientação vai variar de acordo com sua própria titulação, devendo o doutor orientar em torno de oito alunos na elaboração de seus trabalhos acadêmicos, e ainda participar das bancas de seus orientandos e de outras bancas realizadas pelos cursos.

Esse acúmulo de funções talvez possa explicar um fato que se tem percebido em várias bancas examinadoras, seja como participante, seja como ouvinte na plateia. São aqueles professores que assumem atuar como examinadores em bancas, no entanto, atêm-se ao papel de ouvintes, nada arguindo ao candidato ao título, além de não apresentarem qualquer contribuição para a melhoria dos trabalhos.

Acredita-se que os docentes devem conscientizar-se da importância da sua participação em bancas, não só como seu dever acadêmico, mas, sobretudo, por sua enorme responsabilidade na conclusão de trabalhos de boa qualidade, que consista em real contribuição teórica para determinada área do conhecimento, na busca de uma li- 
teratura especializada respeitável e consolidada. Sobre isso, Paganelli (2011) afirma que

[...] cabe a cada individuo realizar uma análise crítica, responsável, tanto do trabalho que está sendo avaliado, como também do conhecimento apresentado pelo aluno, seu domínio sobre o assunto, exigindo, inclusive, a profundidade necessária condizente com a situação na qual se encontra o examinando.

Além disso, o examinador deve assumir essa tarefa como um compromisso importante, não só perante o examinando, mas ainda diante de seus pares, que também participam da banca, todos na busca de uma avaliação justa e correta do trabalho apresentado pelo aluno.

Vale salientar que os membros da banca devem ter domínio sobre o assunto que está sendo apresentado, de forma que os docentes convidados a compô-la tenham a função, inclusive, de ajudar no trabalho final, dando sugestões sobre quais os passos necessários para que o trabalho atinja um nível de excelência.

Uma estudiosa do tema é Mazilli (2009), que tece interessantes considerações sobre em que consiste a orientação de dissertações e teses, fazendo uma reflexão relacionada ao espaço acadêmico, segundo ela, de significativas aprendizagens: as bancas de avaliação das dissertações e teses, assumindo que as bancas fazem parte do processo de orientação. Para ela, essa abordagem dá significativa originalidade às reflexões, pois esta é uma mirada muito pouco contemplada nas análises dos processos formativos nos espaços da pós-graduação.

Recomenda-se que o docente, quando membro de uma banca examinadora, faça uma leitura minuciosa do trabalho, e siga algumas etapas, de maneira criteriosa, conforme a seguir:

(a) Avaliação da adequação do tema e do título do trabalho, se estes aspectos estão de acordo com o âmbito do curso ou da linha de pesquisa; o exame do título deverá ser refeito após a leitura de todo o trabalho, para avaliar sua adequação e representatividade com relação ao conteúdo apresentado;

(b) Leitura do resumo e do abstract: verificar a capacidade de síntese, se o resumo apresenta todas as partes do trabalho, com linguagem adequada, e se a tradução para o abstract está correta; 
(c) Observação da estrutura do trabalho, através do sumário, que apresenta todas as partes do conteúdo desenvolvido e se está certa a utilização de numeração progressiva (seções primárias, secundárias, terciárias, quaternárias);

(d) Verificação da introdução: se inclui a apresentação sucinta do tema, a justificativa, o problema de pesquisa (obrigatório nas dissertações e teses), o objetivo geral e os específicos, levantamento de hipóteses ou pressupostos (casos de pesquisas), e explanação sobre a estrutura do trabalho (seções e subseções ou capítulos e suas partes);

(e) Leitura cuidadosa da fundamentação teórica ou revisão de literatura: coerência dos tópicos, sequência lógica, elo entre as ideias, formas de citação (diretas e indiretas), conferência dos autores citados com as respectivas referências ao final do trabalho; inclusão de esclarecimento sobre delimitação de elementos como período de publicação da literatura lida e idiomas dos trabalhos referenciados.

(f) Procedimentos metodológicos (para pesquisas): tipo de pesquisa, delimitação da pesquisa, universo de estudo, população pesquisada, utilização ou não de amostragem, instrumento de coleta de dados, período de realização da pesquisa, detalhamento das ações desenvolvidas durante o trabalho;

(g) Descrição e análise dos resultados: a análise dos dados coletados deve ser desenvolvida com a retomada de toda a teoria apresentada, devendo-se comparar os resultados obtidos com as ideias dos autores citados. Informação sobre análise quantitativa, qualitativa ou quali/quanti, quanto à inserção ou não de gráficos, tabelas e outras ilustrações, se o texto faz remissivas às ilustrações, apêndices e anexos. Resgate de toda a teoria apresentada, inserindo-se comentários e comparações dos resultados com as ideias dos autores citados;

(h) Considerações ou Conclusões (estas, para casos de pesquisas): nesta parte, deverão ser retomados os objetivos definidos na introdução, para avaliar se foram ou não atingidos, bem como as hipóteses ou pressupostos. Além disso, nesta seção, devem ser destacados os pontos mais relevantes do trabalho.

(i) Recomendações: alguns trabalhos, em seu término, fazem recomendações para futuras pesquisas similares que possam ampliar o estudo;

(j) Redação e estilo: devem ser observados aspectos quanto à superestrutura do texto, como sua macroestrutura (coerência: começo, meio e fim) e sua microes- 
trutura (coesão entre frases e parágrafos) a correção da redação e a adequação do estilo do texto, inclusive a verificação quanto à adoção da linguagem científica, que utiliza os verbos no impessoal;

(k) Normalização: os trabalhos acadêmicos devem seguir as normas adotadas na universidade, sendo que a grande maioria segue as normas da Associação Brasileira de Normas Técnicas (ABNT) específicas para elaboração de trabalhos científicos quanto a: formatação, apresentação, resumos, sumários, citações, referências, ilustrações e outras. Verificação da necessidade de Lista de Ilustrações, Gráficos, Quadros, Siglas e outros, bem como da inserção de Glossário, para conceituação de termos técnicos ou científicos citados ao longo do texto.

(1) Formulação de questões objetivas a serem respondidas pelo candidato ao título. O objetivo é avaliar o conhecimento do aluno e a sua segurança com relação ao seu trabalho. Além disso, o examinador deve incentivá-lo a dar continuidade ao estudo, produzindo novos textos como contribuição à área de atuação.

Feitas todas as anotações mencionadas, torna-se interessante, ainda, a digitação de todos os comentários gerais e pontuais (por páginas), além de eventuais sugestões, para que sejam entregues ao orientador e ao candidato ao título, após o término da defesa. Isso tem o intuito de facilitar a adequação do trabalho às sugestões proferidas pelos membros da banca examinadora.

Paralelamente a esses procedimentos, dois outros pontos a serem levados em consideração são a ética e o relacionamento interpessoal entre os professores que participam de bancas.

Segundo Vasconcelos (2005), nas políticas de formação para o ensino superior, o que se percebe é uma ausência de preocupação com o aspecto pedagógico; normalmente se considera que ser apenas portador do título de mestre e doutor seja suficiente para exercer a docência neste nível de ensino. Ocorre que, no pedagógico, está implícita a dimensão ética da docência.

Sobre a ética, nada custa lembrar a relevância deste conceito em qualquer ambiente profissional, principalmente no ambiente universitário, onde se desenvolvem e se formam futuros profissionais, que irão disseminar o conhecimento adquirido ao longo do período em que frequentam a universidade. 
Tratando-se aqui do conceito ética, de maneira superficial, já que na verdade mereceria um tratado sobre o tema, podem ser sintetizadas algumas ideias, como a de que a dimensão ética é indissociável do trabalho docente, podendo ser lembrada, neste contexto, a questão da consciência e intencionalidade das ações éticas, que são bem caracterizadas por Chauí (1995, p. 337), quando afirma: "Para que haja conduta ética é preciso que haja o agente consciente, isto é, aquele que conhece a diferença entre bem e mal, certo e errado, permitido e proibido, virtude e vício".

Pode parecer inapropriado, mas vale ressaltar, ainda, a necessidade de haver respeito entre os membros de bancas. São professores qualificados e capacitados para fazerem parte de determinada banca examinadora. Como já é esperado, com sua subjetividade, cada um faz uma leitura diferenciada do trabalho em exame, considerando seu conhecimento prévio e sua especialidade. Neste contexto, é normal que surjam ideias consensuais e divergentes sobre o trabalho lido, e essas ideias merecem respeito total por parte dos outros membros da banca. Quem deve ser arguido e questionado, quanto aos propósitos apresentados, é o candidato ao título, não sendo razoável que um membro da banca gaste seu tempo de intervenção, desqualificando os comentários de seus pares, de maneira desrespeitosa e constrangedora, o que em nada contribui para o aprimoramento do trabalho então avaliado.

Em defesa do aluno que está sendo examinado, costuma se pronunciar seu orientador, sempre ao final, após da fala de todos os outros membros da banca. Como ele já acompanha todo o processo de elaboração do trabalho, e dá seu aval para que o mesmo chegue ao momento da defesa, acredita-se que não haja mais questões suas para o aluno, cabendo-lhe, tão somente, apresentar suas impressões sobre o processo de orientação, podendo justificar falhas apontadas por algum examinador, mas procurando enfatizar que serão estudadas e levadas em consideração todas as sugestões e contribuições apresentadas. Além disso, é recomendável que tome o cuidado de agradecer pelos comentários cuidadosos e criteriosos, feitos pela maioria dos que participam desse tipo de evento no ambiente universitário.

\section{REFERÊNCIAS}

CHAUÍ, M. Convite à filosofia. 6.ed. São Paulo: Ática, 1995.

MAZILLI, Sueli. Orientação de dissertações e teses: em que consiste? Araraquara: Junqueira \& Marin E.,2009. 136p. 
PAGANELLI, Celso Jefferson Messias. A função da banca examinadora. Âmbito jurídico.com.br, o seu portal jurídico na internet. v. 14, n.93, out.2011 < Disponível em: www.ambito-juridico.com.br/site > Acesso em 16 de abril de 2013.

VASCONCELOS, Maura Marita Morita. A formação do docente universitário sob o prisma da ética. Tese de doutorado < Disponível em: www.pucpr.br/eventos/educere/educere2008/anais/pdf/752_496.pdf $>$ Acesso em 16 de abril de 2013. 